\title{
An Empirical Study on Influence Mechanism of Consumer Trust on Low-Carbon Purchasing Behavior
}

\author{
Pei Zheng ${ }^{1, a}$, Zhiqi Liu ${ }^{2, b}$ \\ ${ }^{1,2}$ No.13 South Road of Lushan, Yuelu district Changsha city Hunan prov.China \\ a1551946617@qq.com, b105887765@qq.com
}

\begin{abstract}
Keywords:Consumer trust, Low-carbon purchasing attitude, Low-carbon purchasing behavior. Abstract.This paper examines the influence mechanism of consumer trust on consumers' low-carbon purchasing behavior based on the theory of planned behavior. Results show that consumer trust exerts positive impacts on consumers' low-carbon purchasing attitude, subjective norm and perceived behavioral control, which in turn directly influence consumers' low-carbon purchasing intention and indirectly influence consumers' low-carbon purchasing behavior.
\end{abstract}

\section{Introduction}

Climate change has become a rigorous challenge to mankind in the 21 st century. Climate related problems, such as global warming, hazy weather, ozone holes, etc., are making living environment increasingly harsh for human beings. Except for minor external factors like solar radiation fluctuations and volcanic eruptions, greenhouse gases discharged by improper consumption related output are the main cause. Greenhouse gas emission is a very common phenomenon all over the world, especially in China. According to the relevant data, the total amount of $\mathrm{CO}_{2}$ emissions in China in 2013 had exceeded the total emissions in Europe and the United States [1]. In the midst of the increasingly serious climate situation, sense of crisis has made consumers care more about reducing carbon emissions. More and more consumers are beginning to develop awareness of the direct influence of their consumption behavior on environment and are willing to pay more for environment-friendly products than ordinary products [2]. However, although consumers' low-carbon consciousness has grown to a certain extent, but the proportion of consumption pattern transformed from high-carbon to low-carbon isn't very great at present [3]. As for the reason,it mainly stems from inadequate trust consumers have in low-carbon products suppliers in terms of their energy-saving technologies, low-carbon service philosophy and the overall promise of products, which hinders some consumers from purchasing low-carbon products eventually.

To promote more consumers to buy low-carbon products in their daily life, this paper explores the influence mechanism of consumers' low-carbon purchasing behavior from the perspective of trust, aiming at providing useful suggestions for enterprises to implement low-carbon marketing.

\section{Theoretical foundation and research model}

Low-carbon purchasing behavior is one kind of planned and purposeful actions, which is not only impacted by consumers' internal psychological factors, but also by external environment factors and objective conditions. According to the theory of planned behavior, individual behavior is driven by behavioral intention directly, and the latter is primarily under the influence of individual attitude, subjective norm and perceived behavioral control [4]. Previous studies have shown that the theory of planned behavior was heavily applied in the context with uncertainty. Similarly,the theory is also suitable for low-carbon purchasing situation because low-carbon products are less mature in terms of production process and performance stability compared with ordinary products. In addition,low-carbon products are relatively more expensive than ordinary products, which makes consumers produce a higher sense of uncertainty .

Trust is defined as one kind of feeling that individual believes that others ' behavior or the social order will meet his or her wishes [5]. Trust is originally from interpersonal communication field and is viewed as an indispensable element to maintain a good interpersonal relationship. Consumer trust is developed from interpersonal trust and refers to consumer's belief that corporations will 
perform in a manner consistent with expectations regarding expertise, integrity and goodwill to meet their needs [6]. The reason why consumer trust is important in low-carbon purchasing context is that it's helpful to cultivate consumers' positive attitude toward enterprises' low-carbon products, strengthen their subjective norm and improve their perceived behavioral control of purchasing. Fig. 1 presents the theoretical model of this study. There are total of six hypothesis in this model, and the authors assume that they influence each other positively.

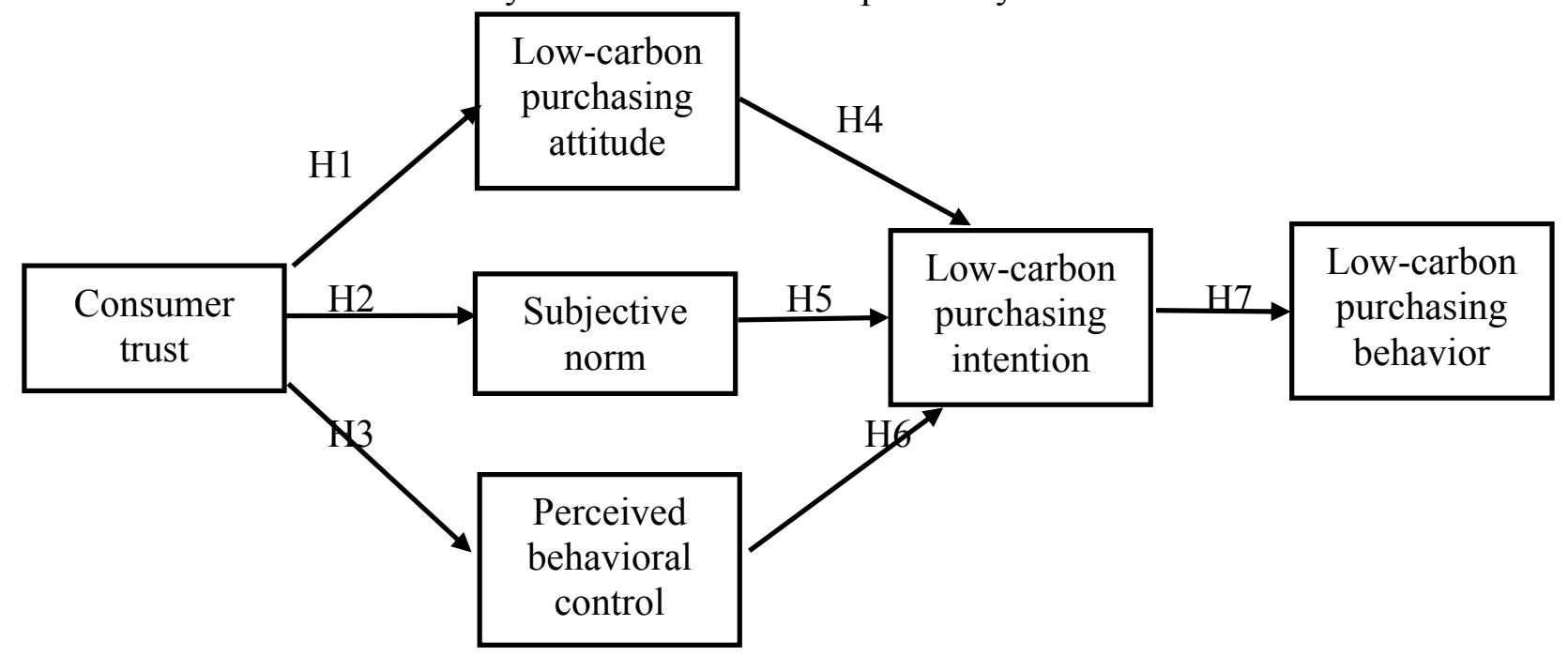

Fig.1 The influence mechanism of consumer trust on consumers' low-carbon purchasing behavior

\section{Methodology}

To make it reflect consumers' daily shopping scenario truly,this paper examines the purchasing behavior of energy-saving air-conditioning. The reason why we choose air-conditioning as the research object is that air-conditioning is relatively more expensive than other products,so consumers will be more cautious and need more trust in the supplier. The questionnaire reflects the actual shopping situation in the form of written material.Considering the bias influence of actual brand on subjects, we set air-conditioning as a virtual brand. The content embodies the provider' expertise,integrity and goodwill adequately. To protrude the moderate price gap between energysaving air conditioning and ordinary air conditioning, we set its price as RMB 3199 (In general, the price of an ordinary air conditioner is between RMB 2099-2899).

Procedure and sample. The participants of this paper were primarily urban consumers in china. Before a formal investigation, we conducted a small-scale investigation to examine the reliability of research instruments. Questionnaires were administered to 200 respondents from central China,mainly in Changsha and Wuhan city. The reliability analysis indicated that the scale possesses good measurement reliability. After that we conducted an official investigation in downtown areas in central, east and south China from June 26 to July 30 in 2015, mainly in Changsha, Wuhan, Shanghai and Shenzhen city. A total of 950 questionnaires were issued and 890 of them were collected. After eliminating 294 invalid questionnaires due to missing data, 596 valid questionnaires constituted the final sample for analysis. The sample consisted of $54.3 \%$ of men and $45.7 \%$ of women. Respondents' age varied from 25 to 65 years.Of the sample, $57 \%$ owned a high salary more than 5000RMB per month.

Measurement. Measures were adopted or derived from previous studies on low-carbon consumption or green consumption for consistency. The dimensions of consumer trust, low-carbon purchasing attitude, subjective norm, perceived behavioral control and low-carbon purchasing intention were measured by seven,three,two,four and three items respectively. A 7-point scale format ranging from (1) "strongly disagree" to (7) "strongly agree" was used for all measures to maximize respondent specificity. Finally, we set a multiple-choice question including 7 items to assess the actual relationship between respondents and energy-saving air conditioning, scoring by 
the highest score.

\section{Analysis and results}

Preliminary analysis. In order to assess the dimension of each construct scale and its reliability, Exploratory Factor Analysis (EFA) using the principal components analysis and Varimax Rotation, coupled with reliability analysis, were performed on the list of 20 items measuring all the constructs. Items with factor loading of less than the absolute value of 0.50 on all factors were eliminated [7]. The internal consistency of the measures was tested by calculating Cronbach's alpha for each construct, where an alpha value of 0.7 or above was considered acceptable or satisfactory. The EFA results led to elimination of one item, leaving a final pool of 19 items.

Measurement model. Confirmatory factor analysis was first conducted to assess the adequacy of the measurement model. The value of $\chi^{2}$ is 164.339 with 92 degrees of freedom, and the rate between $\chi^{2}$ and degree is 1.786 , less than the recommended cutoff of 2 . The Normed-fit index $(\mathrm{NFI}=0.900)$, Goodness-of-fit index (GFI=0.911), the incremental-fit index (IFI=0.954) and the Comparative-fit-index $(\mathrm{CFI}=0.953)$ are above the recommended cutoff of 0.90 , reflecting a good fit of the model to empirical data. Finally, the root mean square error of approximation (RMSEA $=0.064$ ) is smaller than the cutoff value of 0.08 . The fit indexes of the measurement model are all satisfactory indicating that the fit of the empirical data to the hypothesized model is adequate. Table 1 shows that all the correlation coefficient between each two constructs combinations are less than the average variance extracted by the constructs, indicating the discriminant validity is very good.

Table 1. Discriminant validity

\begin{tabular}{ccccccc}
\hline & Trust & Attitude & Norm & Control & Intention & Behavior \\
\hline Trust & 0.635 & & & & & \\
Attitude & $0.526^{* *}$ & 0.772 & & & \\
Norm & $0.448^{* *}$ & $0.655^{* *}$ & 0.498 & & \\
Control & $0.409^{* *}$ & $0.735^{* *}$ & $0.335^{* *}$ & 0.574 & & \\
Intention & $0.393^{* *}$ & $0.717^{* *}$ & $0.421^{* *}$ & $0.541^{* *}$ & 0.848 & \\
Behavior & $0.399^{* *}$ & $0.358^{* *}$ & $0.476^{* *}$ & $0.282^{* *}$ & $0.396^{* *}$ & 0.663 \\
Note:** means p-value $<0.01$. Average variance extracted on diagonal. & & \\
\hline
\end{tabular}

Hypothesis testing. The hypothesized relationships in the proposed research model were simultaneously tested via path analysis. The structural model fits the data adequately $\left(\chi^{2}\right.$ $=155.381, \mathrm{DF}=90, \mathrm{NFI}=0.906, \mathrm{CFI}=0.957, \mathrm{GFI}=0.914, \mathrm{IFI}=0.958$ and $\mathrm{RMSEA}=0.061)$. Table 2 shows that all the hypothesis are supported.

Table 2. Hypotheses test

\begin{tabular}{lcccc}
\hline $\mathrm{H}$ & Path Relationship & Coefficient $(ß)$ & $\mathrm{T}$ & conclusion \\
\hline H1 & Trust $\rightarrow$ Attitude & $0.289^{* * *}$ & 3.168 & support \\
H2 & Trust $\rightarrow$ Norm & $0.500^{* *}$ & 3.836 & support \\
H3 & Trust $\rightarrow$ Control & $0.436^{* *}$ & 5.139 & support \\
H4 & Attitude $\rightarrow$ Intention & $0.717^{* *}$ & 7.728 & support \\
H5 & Norm $\rightarrow$ Intention & $0.340^{* *}$ & 2.313 & support \\
H6 & Control $\rightarrow$ Intention & $0.547^{* * *}$ & 3.555 & support \\
H7 & Intention $\rightarrow$ Behavior & $0.328^{* * *}$ & 4.610 & support \\
Note:*** means $\mathrm{P}<0.001$ and $* *$ means $\mathrm{P}<0.01$. & & & \\
\hline
\end{tabular}

\section{Conclusions}

This paper explores the influence mechanism of consumer trust on consumers' low carbon purchasing behavior. Results show that consumer trust exerts positive impacts on consumers' low-carbon purchasing attitude, subjective norm and perceived behavioral control, which in turn directly influence consumers' low-carbon purchasing intention and indirectly influence consumers' 
low-carbon purchasing behavior. This study have some managerial implications for enterprise managers to implement low-carbon marketing. To promote more consumers to buy low-carbon products, firstly, mangers should strengthen energy-saving technological innovation, set up excellent R\&D teams, participate in the international low-carbon technology communication and cooperation and practice low-carbon products certification, to improve consumers' capacity trust; secondly, managers ought to take consumers' demand of energy conservation into every link of product life cycle and take advantage of advertising, word of mouth marketing, social media and other means to improve consumers' benevolence trust; thirdly, managers must practice good faith management, attach great importance to customer relationship management, inform consumers about product functions truthfully and realistically, and assume their responsibility when something unexpected happened, to improve consumers' trust in their integrity.

\section{Acknowledgments}

This work was financially supported by the Hunan Philosophy and Social Science Foundation (11YBA065) and Humanities and Social Science Youth Research Fund of Ministry of Education(12YJC630318) .

\section{References}

[1] Information on http://worl.163.com/14/0922/08/a6nuut4300014oqq.htm

[2] Xingdong Wang and Fengjie Jing,in Chinese:China Population Resources and Environment, Vol22 (2012), p.47-55

[3] Information on http:// www. Csstoday.net/Item/79973. Aspx

[4] Iceka Jzen: Organizational Behavior and Human Decision Process,No.50(1991), p.179-211

[5] Yefu Zheng,in Chinese: Beijing Social science,No 4(1999), p.118-213

[6] Jongchul Parka,Hanjoon Leeb and Chankon Kim:Journal of Business Research,No.67(2014), p.295-302

[7] Elissar Toufaily, Nizar Souiden and Riadh Ladhari:Journal of Retailing and Consumer Services,No. 20(2013), p.538-548 